\title{
Cardiofaciocutaneous Syndrome
}

National Cancer Institute

\section{Source}

National Cancer Institute. Cardiofaciocutaneous Syndrome. NCI Thesaurus. Code C84617.

A rare genetic syndrome most often caused by BRAF gene mutations. It is characterized by a distinctive facial appearance (high forehead, short nose, and widely spaced eyes), sparse and brittle hair, skin disorders, heart malformations, mental retardation and developmental delay. 